Luc Frenette MD FRCPC,* Daniel Boudreault MD FRCPC, * Joanne Guay MD FRCPC ${ }^{\dagger}$

\title{
Interpleural analgesia improves pulmonary function after cholecystectomy
}

The purpose of this study was to examine the effects of interpleural bupivacaine on analgesia and ventilatory capacity after cholecystectomy. Forty-two patients undergoing elective cholecystectomy were randomly assigned to nwo groups: one to receive interpleural administration of bupivacaine-adrenaline mixture (Group $I=22$ patients) and the other standard administration of intramuscular meperidine (Group $2=20$ patients) for postoperative pain relief. The intensity of pain was evaluated by a visual analogue scale (VAS) preoperatively as well as at 2, 8, 24 and $48 \mathrm{hr}$ postoperatively. At the same time, FVC and FEV 1.0 measurements were obtained for all patients. The group given interpleural bupivacaine had better pain relief with mean VAS of $0.6 \pm 0.9$ (mean $\pm S D$ ) $1.1 \pm 1.4,0.6 \pm 0.9$ and $0.8 \pm 1.2$ compared with $5.2 \pm 2.2,5.8 \pm 2.7,5.5 \pm 2.2$ and $4.5 \pm 1.8$ for patients receiving meperidine $(P<0.001)$. The patients in Group I also had larger FVC and FEV than those in Group 2: FVC $22 \pm 14.5$ per cent vs $32 \pm 15.2$ percent $(P<$ $0.005), F E V_{1.0} 25 \pm 15.5$ vs $38 \pm 14.8$ per cent $(P<0.001)$ (mean $\pm S D$ ). We conclude that the interpleural analgesia can achieve better pain relief with greater ventilatory capacity than a standard analgesic regimen in the first wo days after cholecystectomy.

Le but de cet étude clinique était d'examiner les effets de l'administration interpleurale de bupivacaine sur l'analgésie et les fonctions ventilatoires chez des patients opérés de cholécystectomie. Quarante-deux patients admis pour une cholécystectomie élective ont été distribués au hasard en deux groupes. Le

\author{
Key words \\ ANALGESIA: postoperative; \\ ANAESTHETIC TECHNIQUES: regional, interpleural; \\ ANAESTHETICS, LOCAL; bupivacaine; \\ SURGERY: cholecystectomy; \\ VENTILATION: pOStoperative.
}

From the Centre Hospitalier Hôtel Dicu d'Amos* and Department of Anaesthesia-Reanimation, University of Montreal. $\dagger$

Address correspondence to: Dr. Luc Frennette, 622 e ruc oucst, Amos, Québec J9T 2 S2.

Accepted for publication 20th July, 1990.
Groupe I a reçu de la bupivacaine interpleurale (22 patient.s) et le Groupe 2 a reşu du démérol IM (20 patients). La qualité de l'analgésie étcuit mesurée à l'aide d'une échelle visuelle analogue (VAS) et des tests de fonctions pulmonaires ( $C V$ et VEMS) étaient faits aur tempss suivants ; avant l' intervention et 2, 8, 24 et 48 hre après l'inservention. Une radiographie pulmonaire était faite à la salle de réveil pour tous les patients du Groupe I. Le Groupe I était mieux soulagé tel qu'en témoigne la VAS en post-opératoire: Groupe 1: $0,6 \pm 0,9( \pm S D), 1,1 \pm 1,4,0,6 \pm$ 0,9 et $0,8 \pm 1,2 ;$ Groupe $2: 5,2 \pm 2,2,5,8 \pm 2,7,5.5 \pm 2,2$ et $4.5 \pm 1.8(P<0.001)$. Les fonctions ventilatoires ont été mieur préservées chez les patients recevant la bupivacaine interpleurale tel que démontré par les réductions de la CV $(22 \pm 14.5$ pour cent) et du VEMS $(25 \pm 15,5$ pour cent) observés dans ce groupe comparé au Groupe 2 (diminution de la CV de $32 \pm 15.2$ pour cent et VEMS de $38 \pm 14,8$ pour cent $)(P<0.005$ et $P<$ 0.001 ) ( $\pm S D$ ). Aucun patient du Groupe 1 n'a présenté de pneumothorax. Nous concluons que la bupivacaine interpleurale est une technique puissante d'analgésie. qu' elle préserve mieux la fonction pulmonaire que la mépéridine $I M$ et que le cathéter peut être installé par voie percutanée en toute sécurité.

Upper abdominal surgery, including cholecystectomy, induces alterations of pulmonary function. ${ }^{1-3}$ Parenteral opioids which are used extensively for postoperative analgesia are associated with undesirable side effects. These include hypoxic episodes while the patient is asleep and incomplete and sporadic analgesia. ${ }^{3}$ Several methods have been advocated to reduce these alterations of pulmonary function induced by postoperative pain, including transcutaneous electric nerve stimulation, intercostal blocks, epidural analgesia and most recently interpleural analgesia. ${ }^{4-7}$ Although experience is still limited with the last technique, inserting a catheter using a closed chest technique is questionable because of the reported incidence of pneumothorax which may be as high as 20 per cent. ${ }^{8}$

The present study was designed to determine the efficacy of interpleural bupivacaine compared with intramuscular meperidine for pain relief and preservation of pulmonary function after cholecystectomy. We have also 
evaluated the incidence of pneumothorax using a closed chest technique for interpleural catheter placement.

\section{Methods}

This study was approved by our local Institutional Ethical Committee and informed consent was obtained from 42 ASA physical status I and II patients scheduled to undergo elective cholecystectomy by subcostal incision. The patients were randomly divided into two groups: Group 1 received interpleural bupivacaine and Group 2 received intramuscular meperidine given at a dose of $1 \mathrm{mg} \cdot \mathrm{kg}^{-1}$ every four to six hours as required during the 48 -hr postoperative study period.

All patients received lorazepam (2-4 mg PO) as a premedication 60 to $90 \mathrm{~min}$ before anaesthesia. Anaesthesia was induced with fentanyl $\left(2-5 \mu \mathrm{g} \cdot \mathrm{kg}^{-1}\right)$, thiopentone $\left(4 \mathrm{mg} \cdot \mathrm{kg}^{-1}\right)$ and succinylcholine $\left(1-1.5 \mathrm{mg} \cdot \mathrm{kg}^{-1}\right)$ was used to facilitate tracheal intubation. Anaesthesia was maintained with $\mathrm{N}_{2} \mathrm{O}$ /oxygen (60/40 per cent) and isoflurane with fentanyl as needed. Neuromuscular blockade was achieved with vecuronium, and reversed at the end of the surgical procedure with neostigmine combined with an anticholinergic agent.

After surgery, patients of Group l, while still anaesthetized, were placed in the left decubitus position. Using a 17-gauge Tuohy needle, pleural puncture was made into the eighth right intercostal space at a distance of eight to ten centimeters from the spinal apophysis. The needle was introduced with the bevel in a cephalad direction and advanced until bony contact was obtained at the superior surface of the rib. The stylet was then removed and a glass syringe from which the piston had been removed was filled with preservative-free saline and was attached to the needle. The patient was temporarily disconnected from the respirator to diminish thoracic cage movement during the procedure. The needle was then advanced slowly until a click was perceived indicating penetration of the interpleural space. The negative interpleural pressure caused saline to enter the space. Finally an 18-gauge epidural catheter was inserted five to six centimeters into the space. A slight aspiration was made to ascertain that neither the lung nor a vessel had been punctured. After the catheter was secured in place the patients were brought to the recovery room while still anaesthetized and receiving mechanical ventilatory support.

The analgesic solution was first injected via the interpleural catheter in the recovery room as soon as the patient complained of pain and thereafter every six hours during the $48 \mathrm{hr}$ postoperative study period, regardless of the presence of pain. The patient was placed in the supine position and maintained in this position for $30 \mathrm{~min}$ after injection. Twenty $\mathrm{ml}$, bupivacaine 0.5 per cent (average $1.0-2.0 \mathrm{mg} \cdot \mathrm{kg}^{-1}$ ) containing epinephrine $1: 200,000$ was infused over ten minutes via a syringe pump. If the pain reappeared before six hours, injections of bupivacaine were given every four hours. If this was still insufficient, meperidine $1 \mathrm{mg} \cdot \mathrm{kg}^{-1} \mathrm{IM}$ was given every four hours. Similarly the intramuscular meperidine given to Group 2 patients was started as soon as the patient complained of pain in the recovery room and repeated each four to six hours as needed.

Pain scores were obtained by the attending anaesthetist from the patients in the immediate preoperative period as well as at $2,8,24$ and $48 \mathrm{hr}$ after surgery, using a visual analogue scale (VAS: $0=$ no pain, $10=$ excruciating pain). Pulmonary function was evaluated at the same time intervals by measuring FVC and $F E V_{1}$, the measurement being taken with the patient in the sitting position. A chest $x$-ray was obtained in Group 1 patients on arrival in the recovery room. Also, the level of analgesia was assessed by transcutaneous electric stimulation twice a day, $30 \mathrm{~min}$ after interpleural injection of bupivacaine. The presence of signs and symptoms (restlessness, vertigo, tinnitus, slurred speech, hypotension) compatible with local anaesthetic toxicity were noted by the attending anaesthetist or nurse.

The significance of the differences between the two groups was analysed using unpaired $t$ tests for age, weight, height, sex distribution, obesity, smoking and associated disease. A comparison of the mean VAS, mean FVC and FEV $_{1.0}$ was analysed by ANOVA with repeated measures and paired $t$ test with age, sex distribution and the prevalence of obesity, associated disease and smoking as covariates. Significance was assumed if $P<0.05$.

\section{Results}

A total of 42 patients was studied: 22 in Group 1 and 20 in Group 2. The two groups were comparable with regard to age, sex, obesity (body mass exceeding the ideal weight by 20 per cent), smoking history and associated disease (diabetes, hypertension, chronic bronchitis, coronary heart disease) (Table).

Analgesia was better in Group I patients $(P<0.001)$

TABLE General data

\begin{tabular}{lll}
\hline & $\begin{array}{l}\text { Group 1 } \\
\text { (bupivacaine) }\end{array}$ & $\begin{array}{l}\text { Group 2 } \\
\text { (meperidine) }\end{array}$ \\
\hline Number of patients & 22 & 20 \\
Age (yr) & $51 \pm 16$ & $47 \pm 13$ \\
Weight (kg) & $75 \pm 13$ & $78 \pm 14$ \\
Height (m) & $1.64 \pm 0.09$ & $1.62 \pm 0.09$ \\
Sex (F/M) & $13 / 9$ & $11 / 9$ \\
Obesity & $7 / 22$ & $9 / 20$ \\
Smoking & $16 / 22$ & $15 / 20$ \\
Associated disease & $15 / 22$ & $12 / 20$ \\
\hline
\end{tabular}




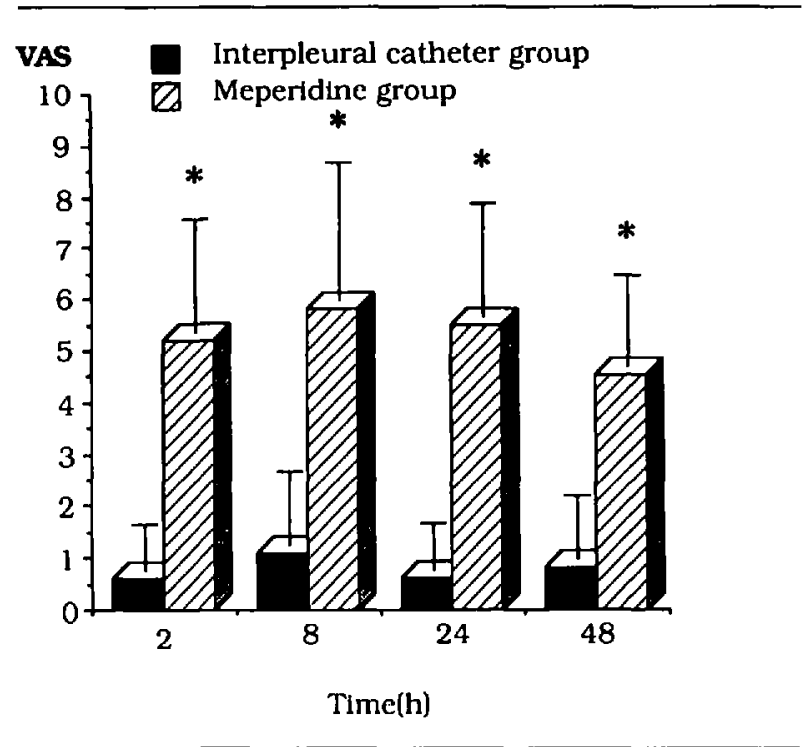

FIGURE 1 Evaluation of pain with a visual analog pain scale (VAS). A score of zero represents no pain and a score of ten represents an excruciating pain. Group 1 was different from Group 2 at all times $(* P<0.001)($ mean \pm SD).

(Figure 1). Only one patient in Group 2 had a VAS score of zero two hours postoperatively while $14,11,17$ and 11 Group 1 patients had scores of zero at 2, 8, 24 and $48 \mathrm{hr}$ respectively. Six patients in Group 1 had a score zero at all time intervals. Eleven of 22 patients of Group 1 needed bupivacaine at 4-hr intervals (range two to six doses) having received two previous injections during the first postoperative $12 \mathrm{hr}$ but none required meperidine for pain relief. Patients of Group 2 received a mean dose of $755 \mathrm{mg}$ meperidine in the first $48 \mathrm{hr}$ post-cholecystectomy (range 520 to $1200 \mathrm{mg}$ ). The degree of sensory analgesia in Group 1 as assessed by transcutaneous electric stimulation was $T_{6}$ (range $T_{4}-T_{7}$ ) to $T_{11}$ (range $T_{9}-T_{12}$ ).

Preoperative assessment of ventilatory capacity was comparable in both groups. Twelve patients in Group 2 had preoperative FVC and FEV 1.0 less than 80 per cent of predicted values compared with nine in Group 1 for FVC and 13 patients for $\mathrm{FEV}_{1.0}$. There was no evidence of increased prevalence of chronic obstructive pulmonary disease in either group. The differences in postoperative FVC and $\mathrm{FEV}_{1.0}$ between Group 1 and Group 2 were not influenced by a preoperative value of FVC and $\mathrm{FEV}_{1.0}<$ 80 per cent of the predicted values.

In the postoperative period decreases in FVC and $\mathrm{FEV}_{1.0}$ were observed in both groups, the lowest values being measured two hours after surgery. The mean FVC two hours after surgery was $1.69 \pm 0.44 \mathrm{~L}$ for Group 1 compared with $1.39 \pm 0.43$ for Group 2. The mean $\mathrm{FEV}_{1.0}$ was $1.19 \pm 0.41 \mathrm{~L}$ in Group 1 and $0.90 \pm 0.28$ in Group 2 (mean \pm SD). At all intervals studied, Group 2
FEV1.0

( $L$ in 1 sec)

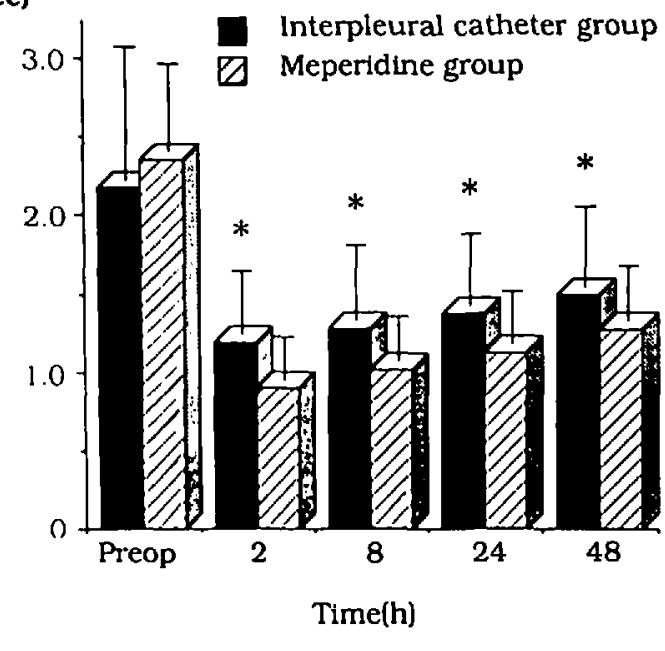

FIGURE 2 Preoperative and postoperative values of FVC versus time. Group 1 was different from Group $2\left({ }^{*} P<0.005\right)$. (mean $\pm \mathrm{SD}$ ).

patients had significantly lower values of FVC ( $P<$ $0.005)$ and $\mathrm{FEV}_{1.0}(P<0.001)$. The largest difference was observed at $48 \mathrm{hr}$ after surgery (Figures 2 and 3 ). These differences in postoperative FVC and FEV 1.0 between Group 1 and Group 2 was not increased for patients with worst ventilatory function (preoperative value of FVC or FEV $1.0<80$ per cent of the predicted values).

There was no pneumothorax on the postoperative chest $x$-ray and no patient had any sign or symptom compatible with local anaesthetic toxicity.

\section{Discussion}

The results of this study demonstrate the effective analgesia obtained in the immediate postoperative period by the injection of interpleural bupivacaine after cholecystectomy. Indeed, six out of 22 patients never complained of pain during the first $48 \mathrm{hr}$ after surgery. This degree of analgesia is rarely achieved using traditional intramuscular opioids. Although a double-blind protocol was not used, we believe that the differences that we observed could not be explained simply by the bias of improved patient care or by a placebo effect. The quality of analgesia obtained in our study is consistent with that reported by others. ${ }^{7-9}$

Ventilatory function was better maintained in patients receiving interpleural bupivacaine as demonstrated by the reduction of FVC ( 22 per cent) and $\mathrm{FEV}_{1.0}$ (25 per cent) observed in this group compared with Group 2 (decreased FVC of 32 per cent and decreased $\mathrm{FEV}_{1.0}$ of 38 per cent). These are in accord with similar reports. ${ }^{8}$ It is not 


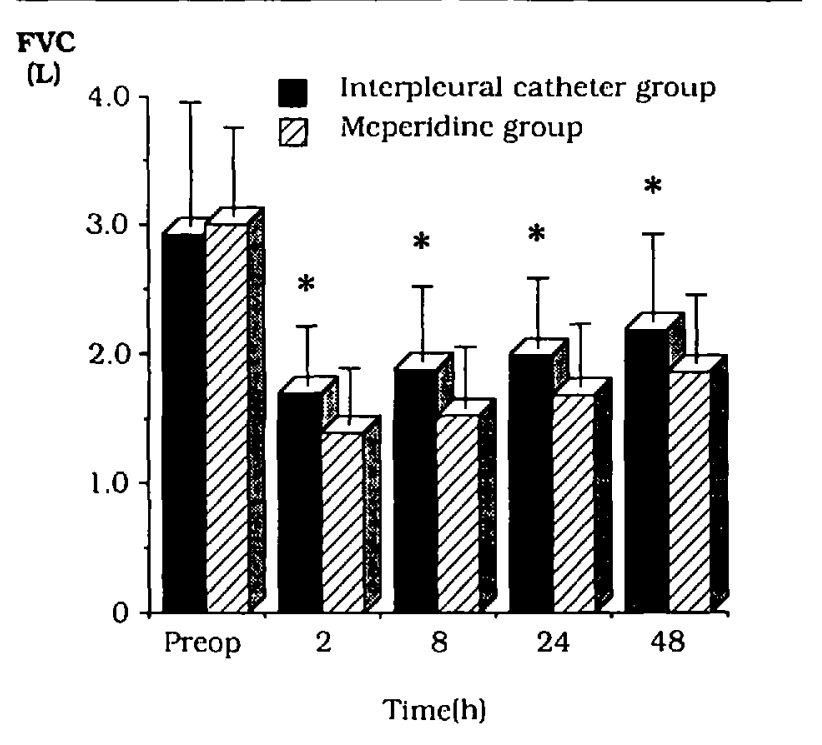

FIGURE 3 Preoperative and postoperative $\mathrm{FEV}_{1,0}$ versus time. Group I different from Group $2\left({ }^{*} P<0.001\right)$. (mean $\left.\pm S D\right)$.

surprising that better analgesia is associated with improved pulmonary function since pain associated with upper abdominal surgery discourages deep breathing and coughing.

In our study, we were not able to demonstrate better preservation of ventilatory capacity in patients with severe abnormalities in their preoperative pulmonary function tests. We suggest that this was because we did not have a sufficient number of patients with severely compromised pulmonary function, that is $\mathrm{FVC}<60$ per cent of the predicted value. In such patients, we assume that better analgesia provided by interpleural bupivacaine would enhance coughing and deep breathing, and hence diminish the incidence of serious pulmonary complications such as atelectasis and pneumonia. The use of interpleural analgesia could then have a positive influence on the global postoperative evolution of patients and particularly those prone to pulmonary complications, though further studies need to be conducted in this subgroup of patients to confirm this assessment.

Many clinicians have been reluctant to use a closed chest technique for the placement of an interpleural catheter because of the high incidence of pneumothorax, ${ }^{8}$ Using our technique, pneumothorax was not seen in our patients as determined by chest $x$-ray in the recovery room. We used a syringe filled with saline instead of a lubricated glass syringe to locate the interpleural space. This may eliminate false negatives caused by sticking between the piston and the syringe wall and thus prevent the needle from being accidently advanced too far into the thoracic cavity.
In conclusion, interpleural analgesia was found to be excellent in alleviating post-cholecystectomy pain. Pulmonary function was maintained better using this form of analgesia. Using the described method, the interpleural catheter was safely introduced by the closed chest technique.

\section{References}

1 Ford GT, Hitelaw WA, Rosental TW, Cruse PJ. Guenter $C A$. Diaphragm function after upper abdominal surgery in humans. Am Rev Respir Dis 1983; 127: $431-6$.

2 Parfrey PS, Harte PJ, Quinlan JP, Brady MP. Pulmonary function in the early postoperative period. Br J Surg 1977; 64: 384-9.

3 Catley $D M$, Thonton C, Jordan C, Lehane JR, Royston D, Jones JG. Pronounced, episodic oxygen desaturation in the postoperative period: its association with ventilatory pattern and analgesic regimen. Anesthesiology 1985; 63: 20-8.

4 Ali J, Yaffec $S$, Serrette $C$. The effect of transcutaneous electric nerve stimulation on postoperative pain and pulmonary function. Surgery 1981; 89: 507-12.

5 Engberg $G$. Respiratory performance after upper abdominal surgery: a comparison of pain relief with intercostal blocks and centrally acting analgesics. Acta Anaesthesiol Scand 1985; 29: 427-33.

6 Staren ED, Cullen ML. Epidural catheter analgesia for the management of postoperative pain. Surg Gynecol Obstct 1986; 162: 389-404.

7 Reiestad F, Stromskag KE. Interpleural catheter in the management of postoperative pain. Reg Anesth 1986; 11: 89-91.

8 Brismar B, Petterson N, Tokics L, Strandberg A, Hedenstierna $G$. Postoperative analgesia with intrapleural administration of bupivacainc-adrenaline. Acta Anaesthesiol Scand 1987; 31: 515-20.

9 Stromskag KE, Reiestad F, Holmqvist ELO, Ogenstad $S$. Interpleural administration of $0.25 \%, 0.375 \%$ and $0.5 \%$ bupivacaine with cpinephrine after cholecystectomy. Anesth analg 1988; 67: 430-4. 